\title{
Aproximações sobre a Transdisciplinaridade: Algumas Linhas Históricas, Fundamentos e Princípios Aplicados ao Trabalho de Equipe
}

Isac Nikos Iribarry ${ }^{1}$

Universidade Federal do Rio Grande do Sul

\begin{abstract}
Resum
O objetivo deste artigo é o de apresentar algumas aproximações conceituais e práticas sobre o tema da transdisciplinaridade. Em um primeiro momento, as aproximações realizadas serão alternadas pela exposição teórica dos temas relacionados à transdisciplinaridade e por algumas ilustracõos práticas dos conceitos. O conceito de disciplina e suas derivações multidisciplinaridade, pluridisciplinaridade, interdisciplinaridade e transdisciplinaridade - serão examinados em suas diferenças e conseqüências para o estabelecimento de relações entre diferentes disciplinas. Em seguida, serão apresentadas algumas origen históricas e alguns fundamentos da transdisciplinaridade. Na etapa final do trabalho, serão examinados os princípios práticos do trabalho de equipe em uma situação de transdisciplinaridade. Tais princípios estão organizados a partir do trabalho em equipe, da geraç̃o de novos dispositivos, da familiarização dos profissionais com cada área diferente da sua, da legibilidade e compartilhamento dos discursos e da tomada de decisão horizontal.

Palavras-chave: Disciplinaridade; transdisciplinaridade; trabalho de equipe.
\end{abstract}

Approaching Transdisciplinarity: Some Historical Lines, Foundations and Applied Principles to Team Work

Abstract

This article aims at presenting some conceptual and practical approaches on transdisciplinarity. At first, all the made approaches will be presented in an alterned way with the theorical presentation of themes related to transdisciplinarity. Some practical illustrations of those concepts will be presented as well. The concept of disciplinarity and its derivations - multidisciplinarity, pluridisciplinarity and transdisciplinarity - are examined in their differences, as well as in their consequences for establishing a relationship between different areas. Following that, some historical origins and foundations of transdisciplinarity will be presented. In the last part of this paper, the practical principles of team work in a case of transdisciplinarity will be discussed. Those principles are organized from the work carried out by the team work, the generation of new devices to foster familiarising of professionals from different areas, the readability and sharing of discourses, as well as horizontal decision making.

Keywords: Disciplinarity; transdisciplinarity; team work.

Atualmente, o tema da transdisciplinaridade tem sido focalizado em diversos contextos de estudo e pesquisa. Desde as teorizações disponíveis com a crescente literatura sobre o assunto até as pesquisas sobre trabalhos de equipe e estilos de interação entre os membros de um determinado grupo. A intenção deste trabalho, no entanto, não é a de enumerar exaustivamente uma série de referências sobre o tema da transdisciplinaridade. A proposta é a de estabelecer um recorte e examinar uma das primeiras reflexões nacionais, a partir de Japiassu (1976), e trazer à luz um apanhado recente sobre os temas relacionados à transdisciplinaridade na perspectiva dos trabalhos desenvolvidos por Nicolescu (1999). Também serão resgatadas algumas informações históricas relacionadas à origem e aos fundamentos da transdisciplinaridade de modo que se possa situá-la na

Endereço para correspondência: Instituto de Psicologia da UFRGS, Laboratório de Psicanálise e Aprendizagem, Ramiro Barcelos, 2600, 90035 003, Porto Alegre, RS, Fone/Fax 33165246. E-mail: nikos@plug-in.com.br ${ }^{2}$ Esse artigo é uma adaptação de parte integrante da tese de doutorado do autor, subsidiada pela CAPES, a qual o autor expressa seus agradecimentos. perspectiva de um estilo de interação grupal para o trabalho de equipes. Convém, antes de mais nada, estabelecer algumas aproximações sobre o termo disciplina e seus derivados inter, multi, pluri e trans.

Segundo Japiassu (1976), é necessário precisar o sentido da disciplinaridade, examinando, em primeiro lugar, o que vem a ser uma disciplina. Para o autor, é necessário que se busque algumas precisões de ordem epistemológica em relação aos dois termos para que se possa chegar a uma diferenciação dos diversos tipos ou modalidades de disciplinaridade. Nessa perspectiva, disciplina terá o mesmo sentido que ciência. Disciplinaridade significará, então, a exploração científica e especializada de determinado domínio homogêneo de estudo. O que nos permite evocar um conjunto sistemático e organizado de conhecimentos com características próprias em seus planos de ensino, de formação, dos métodos e das matérias. Tal exploração tem a finalidade de fazer surgir novos conhecimentos que irão substituir os antigos. Fazer equivaler disciplina e ciência serve, com propriedade, à finalidade de uma definição operacional para o termo disciplinaridade. Mas é preciso lembrar que 
toda ciência é uma disciplina, mas nem toda disciplina é uma ciência. E uma disciplina sempre depende da interação com outras diferentes disciplinas. Assim, é preciso estabelecer níveis de agrupamento para as disciplinas em contato.

O primeiro nível é o da multidisciplinaridade. Sua descrição geral evoca uma gama de disciplinas propostas simultaneamente, mas sem fazer aparecer diretamente as relações que podem existir entre elas. É um tipo de sistema de um só nível e de objetivos múltiplos; não há nenhuma cooperação entre as disciplinas (Japiassu, 1976). Pode-se pensar no seguinte exemplo: em um hospital, vários profissionais estão reunidos, mas trabalham isoladamente. O paciente passa por uma contagem de linfócitos, em seguida é atendido pelo oncologista e, finalmente, dirige-se à sala de quimioterapia. Neste caso não há contato entre os profissionais envolvidos no atendimento: o bioquímico da contagem de linfócitos, o médico oncologista e a enfermeira que cuida da quimioterapia não estão articulados entre si de modo que apareçam relações entre as disciplinas. A ausência de uma articulação não significa, no entanto, uma ausência de relação. O fato é que os profissionais, nesse caso, estão inseridos em um esquema automático, o qual não gera espaço para uma articulação como em outras modalidades da disciplinaridade (Iribarry, 2002).

O segundo nível é a pluridisciplinaridade. Sua descrição geral envolve a justaposição de diversas disciplinas situadas geralmente no mesmo nível hierárquico e agrupadas de modo que apareçam as relações existentes entre elas. É um tipo de sistema de um só nível e de objetivos múltiplos; há cooperação, mas sem coordenação (Japiassu, 1976). Quando, por exemplo, um paciente procura atendimento psiquiátrico e, após receber orientação e prescrição psicofarmacológica, é encaminhado, pelo próprio psiquiatra a um psicólogo para um trabalho de psicoterapia. Os profissionais cooperam, mas não se articulam necessariamente de maneira coordenada. Nesse caso, a cooperação não é automática, mas cumpre a finalidade de estabelecer contatos entre os profissionais e suas áreas de conhecimento (Iribarry, 2002).

$\mathrm{Na}$ interdisciplinaridade, a descrição geral envolve uma axiomática comum a um grupo de disciplinas conexas e definidas em um nível hierárquico imediatamente superior, o que introduz a noção de finalidade. É um tipo de sistema de dois níveis e de objetivos múltiplos com a coordenação procedendo de nível superior (Japiassu, 1976). Pode-se pensar no exemplo de uma equipe para atendimento ambulatorial de gestantes adolescentes de baixa renda. A equipe é formada por um médico pediatra, um médico psiquiatra, um psicólogo, um assistente social, uma psicopedagoga, uma enfermeira e uma secretária. Cada área mencionada agrega ainda estudantes que realizam estágio no ambulatório.
Todavia, o que prevalece é o saber médico, cabendo a coordenação e a tomada de decisão aos profissionais da área médica, que dirigem e orientam a equipe em seu trabalho (Iribarry, 2002).

$\mathrm{Na}$ transdisciplinaridade, a descrição geral envolve uma coordenação de todas as disciplinas e interdisciplinas em um sistema de ensino inovado, sobre a base de uma axiomática geral. É um tipo de sistema de níveis e objetivos múltiplos. A coordenação propõe uma finalidade comum dos sistemas (Japiassu, 1976). Numa equipe de posto de saúde, por exemplo, encontram-se diversos profissionais reunidos. Pode-se tomar como exemplo a equipe que recebe pacientes com problemas mentais. Esta equipe, muito provavelmente, reunirá profissionais como psicólogos, psiquiatras, enfermeiros, assistentes sociais, fonaudiólogos, fisioterapeutas, neurologistas, clínicos gerais, etc. Quando o paciente chega para uma avaliação todos irão assisti-lo e buscarão formular um diagnóstico acerca do caso. Para que esse diagnóstico seja dado em situação de transdisciplinaridade não basta apenas que cada profissional opine a partir de sua área e, finalmente, um tratamento seja indicado. Para que a configuração transdisciplinar seja alcançada é preciso que esses profissionais, fundamentalmente, estejam reciprocamente situados em sua área de origem e na área de cada um dos colegas (Iribarry, 2002).

Para que a configuração transdisciplinar se torne verdadeira é preciso que o psicólogo, por exemplo, seja introduzido na área de seu colega assistente social e na área de seu colega psiquiatra e vice-versa. Ademais, é preciso que cada problema não solucionado em uma das áreas seja levado para uma área vizinha e, assim, seja submetido à luz de um novo entendimento (Caon, 1998). Quando, hipoteticamente, um psicólogo percebe a insuficiência de seus paradigmas no trabalho com o autismo, ele poderá propor ao seu colega neurologista um desafio. Que ali onde a psicologia não consegue formular uma intervenção (e o que resulta disso é uma interrogação), a neurologia possa, com a ajuda das demais áreas que compõem a equipe, iluminar o caminho com alguma proposta de intervenção. Esta é a situação paradigmática para geração de novos dispositivos para o trabalho com o autismo, por exemplo. Todavia, é preciso que psicólogo e neurologista se coloquem humildemente à disposição um do outro e do caso, evitando demorar-se na comum posição de discutir algumas incompatibilidades que podem surgir entre as duas áreas. Nosso exemplo apresenta dois profissionais apenas, mas é importante salientar que isso vale para todos os encontros possíveis entre as áreas que compõem uma equipe de trabalho (Iribarry, 2002). 
A visão piagetiana trazida por Japiassu (1976) demonstra, por si mesma, o quanto é necessário difundir o espírito transdisciplinar. Da etapa das relações interdisciplinares se espera que advenha uma etapa superior, a qual não se restringe ao objetivo de atingir interações ou reciprocidades entre pesquisas especializadas, mas que situa essas ligações no interior de um sistema total, sem fronteiras estabelecidas entre as disciplinas (Piaget, 1972, citado em Japiassu, 1976).

A transdisciplinaridade, de acordo com Caon (1998), é um desafio colocado pelo interesse de uma equipe de profissionais que estão reunidos pela metáfora proposta por uma situação de transdisciplinaridade, na qual cada pesquisador problematiza os conceitos de diferentes campos. Cada um entra na disciplina do colega e olha pela luneta do outro pesquisador, interrogando os dispositivos práticos e teóricos utilizados pelo pesquisador anfitrião e com os quais ele vê aquilo que diz ver. Em transdisciplinaridade, os dispositivos utilizados para equacionar o problema são mais importantes do que a solução do mesmo (Caon, 1998). Cabe salientar que o nível da transdisciplinaridade não é um estilo de interação superior em relação aos demais níveis. Trata-se, pura e simplesmente, de um nível a ser buscado pelos benefícios que traz em sua gestão, mas que preserva as outras modalidades de níveis de funcionamento. Estas modalidades são naturais e fazem parte do funcionamento de qualquer grupo ou equipe que está reunido para desenvolver algum trabalho (Iribarry, 2002).

Por outro lado, podemos evocar os trabalhos de Nicolescu (1999) cuja fundamentação nos fala de três níveis apenas: a pluridisciplinaridade, a interdisciplinaridade e a transdisciplinaridade. A pluridisciplinaridade está preocupada com o estudo do objeto de uma só e mesma disciplina por várias disciplinas simultaneamente. Por exemplo, a Filosofia Marxista pode ser estudada pelo olhar cruzado da Filosofia com a Física, com a Economia, com a Psicanálise e/ou com a Literatura. O objeto pesquisado fica enriquecido e melhor aprofundado em suas concepções; todavia a finalidade última do projeto pluridisciplinar é manter o objeto sempre inscrito no quadro de sua pesquisa original (Nicolescu, 1999). A ambição interdisciplinar é diferente. Ela consiste na transferência dos métodos de uma disciplina à outra e está caracterizada por três graus: 1) grau de aplicação: por exemplo, os métodos da Física Nuclear são transferidos para a Medicina gerando novos tratamentos para o câncer; 2) grau epistemológico: por exemplo, os métodos da lógica formal são transferidos para o estudo da epistemologia do Direito; 3) grau de formação de novas disciplinas: por exemplo, a transferência dos métodos da matemática para o domínio da física engendra a física matemática. O objeto é levado a um novo campo, mas ainda permanece ligado a suas características essenciais (Nicolescu,
1999). A transdisciplinaridade, por seu turno, está preocupada com uma interação entre as disciplinas, onde cada uma delas busca um além de si, um além de toda a disciplina: sua finalidade é a compreensão do mundo presente, de modo que haja uma unidade plural de conhecimentos. Há uma estrutura descontínua de níveis de realidade que determina o espaço descontínuo da transdisciplinaridade, a qual se preocupa com a dinâmica engendrada pela ação de vários e diferentes níveis de realidade ao mesmo tempo (Nicolescu, 1999). Podemos situar como exemplo uma equipe de profissionais reunidos para discussão de políticas de saúde. Esta equipe integra médicos, cidadãos, políticos, sociólogos, filósofos e psicanalistas que se reúnem para o planejamento e a implementação de uma intervenção na rede de saúde pública. A ação de cada profissional, em sua especificidade, contribui para uma visão global do espaço transdisciplinar (Iribarry, 2002).

Mas essa noção de transdisciplinaridade, trazida por Nicolescu (1999), é produto de uma longa caminhada histórica. Para descrevê-la, sucintamente, é necessário apresentar alguns pontos importantes sobre a origem histórica da transdisciplinaridade enquanto dispositivo que incentiva uma nova relação entre as diferentes áreas do conhecimento bem como de seus principais fundamentos.

Origens e Fundamentos da Transdisciplinaridade na Perspectiva do CIRET (Centre International de Recherches et Etudes Transdisciplinaires)

Para um exame das origens e dos fundamentos da transdisciplinaridade, vamos estabelecer uma revisão a partir dos documentos disponibilizados pelo CIRET. O CIRET foi fundado em 1987, em Paris. O CIRET é uma associação cujo objetivo é desenvolver uma nova abordagem científica e cultural para as pesquisas realizadas nas universidades contemporâneas. O CIRET tem em sua direção o físico e cientista Basarab Nicolescu e conta com diversos colaboradores de diferentes áreas.

Para Nicolescu (2000), é muito difícil encontrar uma origem segura para o termo transdisciplinaridade. Para o autor, teria sido Niels Bohr, em um artigo de 1955, sobre a unidade do conhecimento, o primeiro a empregar a expressão ou a idéia da expressão transdisciplinaridade. Todavia, a fonte mais segura é um documento redigido por Piaget (1972, citado em Japiassu, 1976) em um colóquio da UNESCO, de 1972, sobre interdisciplinaridade. É dele a famosa passagem onde se afirma que da etapa das relações interdisciplinares, se pode esperar suceder uma etapa superior que será transdisciplinar, que não se contentará com a obtenção de interações ou reciprocidades entre pesquisas especializadas, mas situará essas ligações no interior de um sistema total, sem fronteiras estáveis entre essas disciplinas. 
O primeiro documento que registrou o interesse oficial de cientistas pela transdisciplinaridade foi a Declaração de Veneza. Escrito em 7 de março de 1986, a declaração foi o comunicado final do colóquio "A ciência diante das fronteiras do conhecimento". Destacam-se os seguintes pontos que compõem o documento que resultou na Declaração de Veneza. As ciências fundamentais (física e biologia) provocaram transformações radicais na lógica e na epistemologia devido às inovações tecnológicas do último século. $\mathrm{O}$ determinismo mecanicista, o positivismo e o niilismo são sentidos como ameaças para a espécie humana. O encontro entre a ciência e as diferentes tradições do mundo permite o surgimento de uma nova visão da humanidade. Surge aí um novo racionalismo e uma nova perspectiva metafísica. Recusa-se qualquer projeto globalizante e qualquet sistema fechado de pensamento. Ciências exatas, ciências humanas, arte e tradição devem promover encontros e trocas. O encontro entre ciência e tradição exige novos métodos de educação. Cientistas e opinião pública devem decidir juntos o destino das novas tecnologias. A UNESCO dever dar prosseguimento a estas iniciativas, estimulando a reflexão dirigida para a universalidade e a transdisciplinaridade.

Após o colóquio acima, o próximo documento que registra a necessidade da transdisciplinaridade saiu do congresso "Ciência e tradição: perspectivas transdisciplinares para século XXI", ocorrido em Paris, de 2 a 6 de dezembro de 1991. As conclusões estabelecidas pelo congresso mencionam um enfraquecimento da cultura mundial. Há um totalitarismo planetário que enfatiza um único caminho à verdade e à realidade. As revoluções conceituais trazidas pela física quântica explodiram as visões tradicionais da realidade determinadas econômica e politicamente por conceitos de determinismo, continuidade e localidade. A transdisciplinaridade não procura o sincretismo entre ciência e tradição, mas sim possíveis interatividades entre os dois campos. A transdisciplinaridade procura ultrapassar a modernidade. Por definição não pode haver especialista transdisciplinares, mas pesquisadores animados por uma atitude transdisciplinar. O desafio da transdisciplinaridade é gerar uma civilização, em escala planetária, movida pela força de um diálogo intercultural.

Em 1994, no convento de Arrábida, em Portugal, saiu a Carta de Transdisciplinaridade, adotada no Primeiro Congresso Mundial da Transdisciplinaridade. Desta carta, com 15 artigos, pode-se destacar o reconhecimento da existência de diferentes níveis de realidade, regidos por lógicas diferentes. Qualquer tentativa de reduzir a realidade a um único nível regido por uma única lógica não se situa no campo da transdisciplinaridade. A transdisciplinaridade é complementar à aproximação disciplinar: faz emergi da confrontação e do contato entre as disciplinas dados novos que as articulam entre si; surge uma nova visão da natureza e da realidade. A transdisciplinaridade não procura o domínio sobre várias outras disciplinas, mas a abertura de todas elas àquilo que as atravessa e as ultrapassa. A visão transdisciplinar está resolutamente aberta na medida em que ela ultrapassa o domínio das ciências exatas por seu diálogo e sua reconciliação não somente com as ciências humanas mas também com a arte, a literatura, a poesia e a experiência espiritual. Rigor, abertura e tolerância são características fundamentais da atitude e da visão transdisciplinar. $\mathrm{O}$ rigor na argumentação, que leva em conta todos os dados, é a barreira às possíveis distorções. A abertura comporta a aceitação do desconhecido, do inesperado e do imprevisível. A tolerância é o reconhecimento do direito às idéias e verdades que podem se contrariar entre diferentes disciplinas.

Em 1997, de abril a maio, em Locarno, na Suíça, um novo documento saiu do Congresso Internacional "Que universidade para o amanhã? Em busca de uma evolução transdisciplinar da universidade". Deste congresso foram encaminhadas as seguintes considerações. Os três pilares da transdisciplinaridade são os níveis de realidade, a lógica do terceiro incluído e a complexidade, os quais determinam a metodologia da pesquisa transdisciplinar. A disciplinaridade, a pluridisciplinaridade, a interdisciplinaridade e a transdisciplinaridade são as quatro flechas de um único arco: o do conhecimento. A transdisciplinaridade não é neutra, ela opta pelo sentido. Uma educação neutra e objetiva não passa de um fantasma que foi legado pela ideologia cientificista. A transdisciplinaridade tem como ambição a unificação, em suas diferenças, do objeto e do sujeito: o sujeito conhecedor faz parte integrante da natureza e do conhecimento.

Finalmente, em novembro de 1997, Basarab Nicolescu pronuncia a conferência "Evolução transdisciplinar da universidade: condição para o desenvolvimento sustentável”, na universidade Chulalongkorn, em Bangkok, Tailândia. Destaca-se desta conferência o seguinte ponto: na presença de vários níveis de realidade, o espaço entre as disciplinas e além das disciplinas está cheio, assim como o vácuo quântico está cheio de possibilidades: da partícula quântica às galáxias, do quark aos elementos pesados, que condicionam o aparecimento da vida no universo. A estrutura descontínua dos níveis de realidade determina a estrutura descontínua do espaço transdisciplinar, que por sua vez explica porque a pesquisa transdisciplinar é radicalmente distinta da pesquisa disciplinar, mesmo quando totalmente complementar. A pesquisa disciplinar diz respeito, na melhor das hipóteses, a um único e mesmo nível de realidade; além do mais, na maioria dos casos, refere-se a apenas um fragmento de um nível de realidade. Por outro lado, a transdisciplinaridade diz respeito à dinâmica engendrada pela ação de diferentes 
níveis de realidade ao mesmo tempo. A descoberta destas dinâmicas passa necessariamente pelo conhecimento disciplinar. Embora não se trate de uma nova disciplina ou de uma nova superdisciplina, a transdisciplinaridade é nutrida pela pesquisa disciplinar; ou seja, a pesquisa disciplinar é esclarecida de maneira nova e fecunda pelo conhecimento transdisciplinar. Nesse sentido, a pesquisa disciplinar e transdisciplinar não são antagônicas, mas complementares (Nicolescu, 1997).

Uma questão fundamental para o entendimento da transdisciplinaridade é colocada por Nicolescu (2000) e diz respeito aos diferentes níveis de realidade. Por nível de realidade Nicolescu entende um conjunto de sistemas que são invariantes e regidos pela ação de regras gerais. $O$ mundo quântico está subordinado às leis quânticas, as quais são radicalmente diferentes das leis que regem o mundo macrofísico. Temos, portanto, dois níveis de realidade diferentes quando dois conjuntos de sistemas estão subordinados a leis diferentes e que somente servem ao seu nível de realidade. Nicolescu salienta que a matemática nos permite estabelecer uma descontinuidade entre o nível quântico e o nível macrofísico, de modo que a passagem de um nível a outro continua impossível, o que não impede a co-existência dos dois níveis. Outro aspecto importante das idéias de Nicolescu é o de que os níveis de realidade, em transdisciplinaridade, são radicalmente diferentes daqueles enfatizados pelas abordagens sistêmicas. O que justifica esta diferença é que os níveis de realidade da abordagem sistêmica estão subordinados a leis que são aplicáveis aos diferentes níveis do sistema, ao passo que a transdisciplinaridade resgata níveis de realidade cuja diferença está baseada na tradição de cada nível e suas idiossincrasias. Por isso, diferentes níveis de realidade podem apenas coexistir, sem nunca fazer parte de um sistema ou conjunto de sistemas.

Bourguignon (2001) entende a transdisciplinaridade como um esforço para integrar ao conhecimento tudo aquilo que não pode ser explicado pelo domínio de uma única disciplina, de modo a se recolocar o homem no centro do conhecimento. $\mathrm{O}$ autor ressalta ainda que quando se fala de diferentes níveis de realidade é preciso entender de que realidade se trata. Realidade é aquilo que resiste à representação, à descrição e à imagem. Nível é um conjunto de sistemas naturais e invariantes sob ação de certas leis.

Para haver transição de um nível de realidade para outro é preciso antes reconhecer o fosso que parece existir entre diferentes disciplinas. A transição se pode pensar através da noção de movimento. O movimento do pesquisador de um campo para outro. Todavia, um movimento que não descaracteriza o sujeito pesquisador. A realidade local do sujeito pesquisador revela, portanto, um destaque, uma saliência, um relevo no interior do conhecimento globalizado.
Camus (2001) sugere a implementação de grupos de pesquisa em epistemologia da transdisciplinaridade, enfatizando a necessidade de revisão dos paradigmas universitários. Ademais, o autor situa o projeto da transdisciplinaridade como uma necessidade urgente para as universidades. Não deixando, no entanto, de revelar uma face de projeto utópico. Geralmente, o utópico é grandioso, por isso retorna a prescrição heraclitiana de que são os grandes projetos que permitem alguma possibilidade de êxito. Há que diferenciar ainda, segundo Camus, entre a busca científica e a comunicação desta busca. Isso envolve uma epistemologia essencial, aquela do ato de conhecer. Na busca, o ato de conhecer é que dirige a relação entre sujeito e objeto.

Passet (2001) fala de uma ética da responsabilidade, em que o desenvolvimento da transdisciplinaridade deve ser sempre tomado como algo que parte do pesquisador que este, quando inserido numa tradição de intercâmbio com outras áreas, deve cultivar uma atitude de abertura e contato com o estrangeiro. Paul (2001) fala de cultura e educação como derivados desta ética da responsabilidade, já que são dois aspectos que decorrem do desenvolvimento transdisciplinar, pois são diferentes áreas de conhecimentos, disciplinas, que compõem a cultura e a educação de um povo.

A partir dessa apresentação abreviada das origens históricas da transdisciplinaridade e seus principais fundamentos, logo se percebe a importância de haver um diálogo entre diferentes áreas de conhecimento. Todavia, esse diálogo será muitas vezes pautado pela necessidade de refletir sobre a solução de um determinado problema. Um determinado problema não resolvido em um campo de conhecimento e que é levado para uma outra área de conhecimento, de modo que se instaure um diálogo a partir das dificuldades trazidas pelo problema e do desafio que sua solução representa.

\section{O Problema como Solução}

Caon (1998) salienta que todo o problema não resolvido em uma área deve ser levado a uma área vizinha. Quando um pesquisador está às voltas com um problema não solucionado em sua área temática é preciso que a transdisciplinaridade seja evocada para instaurar um diálogo com outras áreas temáticas. Este diálogo deve promover trocas e aproximações entre os pesquisadores, de modo que o problema não solucionado possa ser compartilhado e, com isso, novas equações e soluções para o problema sejam geradas. Este é o verdadeiro sentido da produção de tecnologias em um domínio de diversidades representado pelo agrupamento de diferentes áreas de conhecimento (Caon, 1998). Assim sendo, a transdisciplinaridade é um 
dispositivo que faz avançar as relações entre as áreas de conhecimento. Se o problema não resolvido em uma determinada área de conhecimento é, como vimos acima uma solução viável para o estabelecimento do diálogo entre as diferentes áreas de conhecimento e pesquisa, então surge à frente daqueles que desejam levar adiante o desafio da transdisciplinaridade a necessidade de trabalhar em equipe. Com a crescente globalização do conhecimento em todas as áreas possíveis e as exigências renovadas a cada dia para que os pesquisadores estejam conectados ao volume formidável de informações que a rede internacional de computadores disponibiliza, é justificável a urgência de um contato mais aprimorado entre os pesquisadores. A transdisciplinaridade é um dispositivo que permite justamente essa integração dos pesquisadores e suas diferentes áreas de conhecimento e pesquisa. A reclusão de pesquisadores de áreas de conhecimento diferentes em guetos fechados é um problema que atinge uma das premissas básicas do estabelecimento de um universo de conhecimentos que pretende dar conta do ser humano numa perspectiva global e integradora de suas contradições naturais e diferenças inevitáveis, de modo que se possa reconhecê-lo como um ente complexo cuja riqueza está justamente na diversidade radical e constituinte de sua subjetividade. Ora, não é essa mesma diversidade radical que atravessa o campo vasto de conhecimentos com sua vasta gama de orientações teóricas, metodológicas e de práticas de pesquisa? E mais: não é exatamente um conjunto de contradições naturais e diferenças inevitáveis que afloram quando as diferentes áreas de conhecimento são colocadas lado a lado numa perspectiva dialógica?

O problema que surge é que o mecanismo da comparação conduz a um afastamento recíproco dessas diferentes áreas, quando deveria instituir o motivo fundamental para a necessária aproximação entre elas, ja que isso não é senão o reflexo do complexo objeto de pesquisa: o ser humano. Assim, pode-se retomar a idéia que é a de levar um problema não resolvido de uma área para outra área, de modo que possa nascer daí um diálogo Um diálogo cujo fundamento principal seja transdisciplinaridade, ou seja, o respeito à coordenação descentralizada e a cooperação sem decisões verticalizadas, bem como o respeito aos diferentes níveis de realidade de cada área, as quais estão regidas por diferentes tipos de lógica.

A origem da transdisciplinaridade está situada no trabalho de equipe. Independente da modalidade - pluri, multi, inter ou transdisciplinar - o que é vital para uma formulação originária da transdisciplinaridade é a reunião de diverso profissionais em um trabalho integrado de equipe. Mas não basta apenas uma equipe coordenada, colaborativa e com uma finalidade. É preciso que haja algo mais. É preciso que haja um compromisso com a geração de dispositivos renovados para o trabalho realizado. É preciso também que cada membro da equipe esteja o mais familiarizado possível com a diversidade de disciplinas e que freqüente continuamente as disciplinas de seus colegas. Ademais, é preciso que os discursos se tornem legíveis e não mais se tornem exercícios velados e obscuros. Uma questão psicofarmacológica complexa deverá ser exposta com a mesma clareza que uma orientação diagnóstica do serviço social, por exemplo. Isso nos permite entrever a necessidade do abandono do jargão com que cada disciplina institui seu saber. A comunicação entre os membros da equipe, portanto, não seguirá mais um modelo verticalizado, baseado na liderança de um saber sobre outro(s), mas deverá assumir uma característica horizontal, onde todos, igualmente, compartilham de seus conhecimentos e saberes. Dessa maneira, a tomada de decisão em relação ao que está sendo discutido será uma tomada de decisão horizontal, onde não há prevalência de um saber sobre outro ou sobre os demais (Iribarry, 2001).

Assim, podemos ver surgir um novo diálogo entre as diferentes áreas de conhecimento e pesquisa. Para trazer à luz esse diálogo é preciso um método. Tal método terá de cumprir algumas proposições básicas que se procuram enumerar a seguir através dos cinco princípios práticos da transdisciplinaridade: trabalho em equipe; geração de novos dispositivos; familiarização dos profissionais com cada área diferente da sua; legibilidade e compartilhamento dos discursos e tomada de decisão horizontal.

\section{Os Princípios Práticos da Transdisciplinaridade no} Trabalho de Equipe

Uma equipe será transdisciplinar quando sua reunião congregar diversas especialidades com a finalidade de uma cooperação entre elas sem que uma coordenação se estabeleça a partir de um lugar fixo. É claro que isso gera, de saída, um problema. Como evitar a verticalidade de uma coordenação? Isto é, como evitar que uma especialidade se torne uma espécie de juiz no processo de tomada de decisão? Ora, a transdisciplinaridade deve ser encarada como meta a ser alcançada e nunca como algo pronto, como um modelo aplicável, e como um desafio que serve de parâmetro para que todos os membros da equipe estejam atentos para eventuais cristalizações e centralizações do poder (Iribarry, 2002).

Por exemplo, numa equipe de unidade psiquiátrica é muito comum se observar um funcionamento bastante integrado, interdisciplinar. Mas qual é a barreira que se encontra aí para que a transdisciplinaridade floresça? É comum observar no trabalho das equipes a presença de técnicos mais antigos e que, por isso, estão mais envolvidos 
com a liderança do trabalho. Algumas vezes, é verdade, seu trabalho é realmente mais incisivo por ser mais antigo, o que lhes dá mesmo condições de tomar boas decisões ou influenciar seus colegas na tomada de uma decisão adequada. Outras vezes, no entanto, o técnico mais antigo sofre das mesmas inseguranças que seus colegas de menor tempo na equipe sofrem. É muito comum acontecer de o técnico tratado como líder encontrar dificuldades de compartilhar de suas dificuldades, pois teme decepcionar seus colegas. Há ainda a questão de uma liderança necessária. É o caso do chefe de equipe. O chefe de equipe ocupa o lugar de líder e isso pode trazer conseqüências de diversas naturezas. Entre elas, talvez as principais e mais comuns, estão o exercício vaidoso da liderança e o conflito natural que as diferenças pessoais e profissionais entre os membros acarretam. Por isso que a transdisciplinaridade mais que um perfil ideal é uma meta que a equipe deverá estabelecer para poder viver um permanente processo de avaliação de seu próprio trabalho nas diferentes perspectivas que a atravessam. Mas é importante lembrar: não se deseja dizer que as lideranças e as chefias de equipe são totalmente nocivas. Acima de tudo, é preciso salientar a necessidade destas lideranças e chefias buscarem incessantes questionamentos acerca de suas posições e estimularem o debate entre os demais membros da equipe. Pode-se pensar no seguinte exemplo: muitas vezes, o estagiário que chega para trabalhar na equipe recebe um lugar pré-fixado. É o lugar de quem deve aprender, certamente, mas não deixa de significar um olhar novo, estrangeiro, de quem chega e pode vislumbrar as coisas com algumas sutilezas que muitas vezes escapam aos profissionais mais antigos. Pode-se sugerir ainda o exemplo daquela equipe que cria e sustenta um imaginário onde uma determinada especialidade é portadora de uma voz que ensurdece as outras especialidades. Assim sendo, toda a equipe abre mão de seus discursos singulares para fazer coro com aquela especialidade que está mais investida de poder de decisão. $O$ trabalho em equipe numa perspectiva transdisciplinar requer humildade e disponibilidade por parte de cada profissional, pois é, em suma, um movimento de reconhecimento de posições diferentes em relação a um mesmo objeto.

Gerar novos dispositivos é a segunda meta a que um trabalho transdisciplinar deve se inclinar. Mas o que são novos dispositivos? Novos dispositivos são conhecimentos que resultam de uma discussão compartilhada acerca do problema que exige solução. Muitas vezes, o novo dispositivo não é a solução, mas um passo fundamental para que se possa encontrá-la. O mais importante para a geração de novos dispositivos é que os profissionais possam se ajudar reciprocamente em suas dificuldades. Para que um novo dispositivo encontre lugar, é preciso, em primeiro lugar, muita humildade e reconhecimento de dificuldades insolúveis no campo em que o problema se origina. Quando um profissional falha em sua intervenção ou sequer consegue formulá-la, este é o momento ideal para que um novo dispositivo possa ser gerado. Mas de que forma? Ora, cabe ao profissional levar seu problema à casa de uma especialidade vizinha (ou de várias) e esperar que o problema, até então insolúvel em sua área, seja examinado e colocado sob o foco de outras intervenções (Caon, 1998). Assim, uma troca de informações será estimulada e aquilo que uma determinada área tem como insolúvel poderá revelar detalhes ainda não percebidos.

Quando profissionais de diferentes áreas estão reunidos em equipe é preciso, portanto, que estejam familiarizados com as diferenças entre eles e suas respectivas áreas de conhecimento. Mas não estamos falando de uma familiarização superficial. É preciso que cada profissional descubra um interesse e uma curiosidade pela área de seu colega. Quando uma equipe está reunida e deseja optar por um funcionamento transdisciplinar é preciso que cada membro exponha suas ferramentas de trabalho, suas teorias, seu entendimento do caso e também exija de seu colega a mesma exposição (Iribarry, 2002). Mas tais exposições não podem ser esotéricas, herméticas, pois o objetivo é que os discursos sejam compartilhados e para isso acontecer é preciso que estes sejam, em primeira instância, acessíveis e legíveis, de modo que produzam ressonâncias naqueles que os recebem. O que evoca a necessidade de uma legibilidade dos discursos.

Para que o intercâmbio entre os pesquisadores seja transdisciplinar é preciso que os discursos - técnicos e ligados ao chamado jargão de cada área - sejam compartilhados (Iribarry, 2002). Mas não basta apenas levar ao colega aquelas palavras que em nosso campo são elementares. É preciso realizar um cuidadoso trabalho de tradução e explicação do que se deseja dizer em cada discurso das áreas envolvidas na situação de transdisciplinaridade. É preciso que o discurso de cada disciplina seja legível para as outras disciplinas envolvidas.

A tomada de decisão é o aspecto culminante de uma orientação transdisciplinar para o trabalho em equipe. É preciso que a decisão seja tomada sem que nenhum saber prevaleça sobre outro, por isso a necessidade de ser horizontal, numa linha em que todos os profissionais estejam reunidos e dêem a sua contribuição de maneira compartilhada (Iribarry, 2002). Na verdade, a tomada de decisão está ligada a um conjunto de decisões que emanam de todas as áreas implicadas no trabalho em equipe. Não se trata do que cada área acredita ser adequado para o caso, mas sim daquilo que o próprio caso irá demonstrar como urgente e necessário para cada área de conhecimento envolvida. 


\section{Considerações Finais}

Como vimos, a transdisciplinaridade está preocupada com uma interação entre as disciplinas, na qual cada uma delas busca um além de si, um além de toda a disciplina: sua finalidade é a compreensão do mundo presente, de modo que possa haver uma unidade plural de conhecimentos. Há uma estrutura descontínua de níveis de realidade que determina o espaço descontínuo da transdisciplinaridade, a qual se preocupa com a dinâmica engendrada pela ação de vários e diferentes níveis de realidade ao mesmo tempo Assim, o trabalho de equipe, que reúne diferentes disciplinas, pode ser colocado na perspectiva transdisciplinar através de princípios práticos que promovem o contato entre essas disciplinas. A transdisciplinaridade visa promover um diálogo entre diferentes áreas do conhecimento e seus dispositivos O diálogo serve como ensejo para uma situação de cooperação entre as diferentes áreas. Transdisciplinaridade é, portanto, diálogo e cooperação entre diferentes áreas do conhecimento.

\section{Referências}

Bourguignon, A. (2001). De la pluridisciplinarité a la transdisciplinarité. Bulletin interactif du CIRET (Centre de Recherche et Etudes Transdisciplinarite), $15,120-127$

Camus, M. (2001). Quelle université pour demain? Bulletin interactif $d u$ CIRET (Centre de Recherche et Etudes Transdisciplinarité), 15, 89-92.

Caon, J. L. (1998). Da existência analfabética à existência analfabetizada. Revista do GEEMPA, 6, 37-70.

Centre de Recherche et Etudes Transdisciplinarité (1986, março). Declaração de Veneza. Comunicado final do colóquio "A ciência diante das fronteiras do conhecimento".
Centre de Recherche et Etudes Transdisciplinarité (1991, dezembro). Ciência e Tradicão: Perspectivas transdisciplinares para o século XXI. Comunicado final. Paris, França.

Centre de Recherche et Etudes Transdisciplinarité (1994). Carta de Transdisciplinaridade. Primeiro congresso mundial da transdisciplinaridade. Arrabida, Portugal.

Centre de Recherche et Etudes Transdisciplinarité (1997, abril/maio). Congresso de Locarno. Que universidade para o amanhã? Locarno, Suíça. Centre de Recherche et Etudes Transdisciplinarité (1997). Responsabilidade das universidades para com a sociedade. Quarta conferência trimestral. Chulalongkorn University, Tailândia.

Iribarry, I. N. (2001). O diagnóstico transdisciplinar em psicopatologia (ensaios de Analitica Existencial, Metapsicologia e Apresentasãa Psicanalitica de Pacientes Analitica Existencial, Metapsicologia e Apresentacáo Psicanalitica de Pacientes
enquanto fundamentos de sua demonstracáa). Projeto de Doutorado nãoenquanto fundamentos de sua demonstração. Projeto de Doutorado não-
publicado, Curso de Pós-Graduação em Psicologia do publicado, Curso de Pós-Graduação em Psicologia do
Desenvolvimento, Universidade Federal do Rio Grande do Sul. Porto Alegre, RS.

Iribarry, I. N. (2002). O Diagnóstico Transdisciplinar como dispositivo para o trabalho de inclusão. Em C. R. Batista \& C. Bosa (Orgs), Autismo e educação: Reflexões e proposta de intervencão (pp. 73-91). Porto Alegre: Artmed.

Japiassu, H. (1976). Interdisciplinaridade e patologia do saber. Rio de Janeiro: Imago.

Nicolescu, B. (1997). La Transdisciplinarité, manifeste. Paris: Éditions du Rocher. Nicolescu, B. (1999). Manifeste sur la transdisciplinarité. Bulletin interactif du CIRET (Centre de Recherche et Etudes Transdisciplinarité, 10, 34-40.

Nicolescu, B. (2000). Transdisciplinarity and complexity: Levels of reality as source of indeterminancy. Bulletin interactif du CIRET (Centre de Recherche et Etudes Transdisciplinarité, 15, 71-75.

Passet, R. (2001). Le dévelopment durable: De la transdisciplinarité a la responsabilité. Bulletin interactif du CIRET (Centre de Recherche et Etudes Transdisciplinarité), 15, 170-176.

Paul, P. (2001). Les different niveaux de realité entre science et tradition. Bulletin interactif du CIRET (Centre de Recherche et Etudes Transdisciplinarite), $17,23-27$.

Recebido: 03/10/2002 $1^{a}$ Revisão: 24/02/2003 Aceite Final: 18/03/2003

Sobre o autor

Isac Nikos Iribarry é Psicanalista e Escritor. É Mestre e doutorando em Psicologia do Desenvolvimento pelo Programa de Pós-Graduação em Psicologia do Desenvolvimento da Universidade Federal do Rio Grande do Sul. 